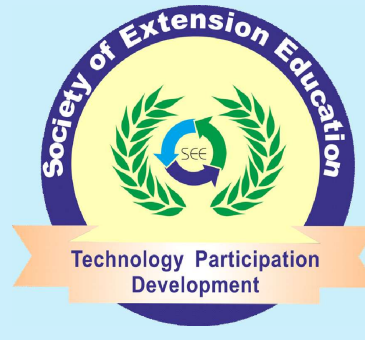

Research Article

\section{Indian Research Journal of Extension Education}

ISSN: 0972-2181 (Print), 0976-1071 (Online)

NAAS Rating : $\mathbf{5 . 2 2}$

Journal homepage: seea.org.in

https://doi.org/10.54986/irjee/2022/jan_mar/1-7

\title{
Livelihood Security of An Isolated Gothi Koya Tribe in Telangana State
}

\author{
Alam Prashanthi ${ }^{1}$ and R. Geetha Reddy ${ }^{2}$ \\ 1. Ph.D. Scholar, 2. Prof. \& Head, Department of Extension Education and Communication Management, \\ College of Community Science, PJTSAU, Hyderabad, Telangana \\ Corresponding author e-mail : prashu.alam@gmail.com
}

Paper Received on August 10, 2021, Accepted on November 20, 2021 and Published Online on January 01, 2022

\begin{abstract}
Tribes are a weaker section of society due to their low social and economic standing. Even in the contemporary day, some tribal groups remain geographically isolated and live in the jungles. One of them is the Gothi koya tribe. Therefore, an attempt was made to study the profile characteristics and livelihood security of Gothi Koya tribe. The study was conducted in Mulugu district, Telangana State with an ex-post facto research design. A total of 60 samples from three villages under ITDA (Integrated Tribal Development Agency), Eturnagaram were selected purposively for this study. Results revealed that half of the respondents (50\%) fall under the age group between 2030 years and the majority (85\%) of the respondents were illiterates. There was a strong positive significant relationship between education and livelihood security at $1 \%$ level of significance $(p<0.01)$ and other independent variables found no significance at $5 \%$ level $(p<0.05)$.
\end{abstract}

Key words : Livelihood security; Food Security; Health and sanitation security; Water security.

$\mathbf{H}_{\text {ousehold livelihood security is described as }}$ appropriate and sustained access to income and resources to satisfy basic requirements (including adequate access to food, drinkable water, health care, educational opportunities, housing, and time for community engagement and social integration) (Frankenberger, 1996). The risk of livelihood failure determines the level of vulnerability of a household to income, food, health and nutritional insecurity. The greater the share of resources devoted to food and health service acquisition, the higher the vulnerability of the household to food and nutritional insecurity (Chambers, 1989). When people are able to utilize, produce, protect, exchange and benefit from the resources and assets then they have livelihood security.
Tribal people are docile, simple, honest and hardworking. But economically, they are exploited, physically oppressed, socially ostracised and culturally isolated. They were also economically poor and backward, socially segregated and humiliated and they have very little education to understand issues in right perspective (Shincy, 2009).

The Gothi koya tribe is one of these weaker sections of the society with their traditional skills and resources. They were referred to as nomadic in society since they lacked the necessary habitat to live in one area. Almost a million Gothi Koyas have fled Chhattisgarh, half to neighbouring regions in Maharashtra and Orissa, and the rest to Telangana's Khammam and Warangal districts. Due to violent threats from the Maoists, the 
police, and the Salwa Judum, these indigenous people abandoned their villages in Dantewada mandal of Bijapur district and from other border districts in Chattisgarh and live with nature and lead a simple life. When they left, they took their children with them, along with a few clothes, utensils, and small animals (Radhakrishnan et al., 2017). Leaving behind a past, families of the displaced Gothi Koyas, are struggling to build a new livelihood in the villages.

Hence, there is a need to study the profile characteristics and livelihood security of the Gothi Koya tribe, which will be utilised to influence development discourse and advocate policies for scrutinising livelihoods. Such studies will help to gain a better understanding of the conditions of the tribal poor. This understanding is important for influencing the process of making development interventions more successful, both at the design and implementation levels. As a result, this study is intended to measure their livelihood security with the following objectives :

i. To study the profile characteristics of selected target population

ii. To know the livelihood security of selected target population

iii. To find out the association between profile characteristics and livelihood security

\section{METHODLOGY}

The purposive sampling procedure was followed for this study. In the present study ITDA Eturnagaram, Mulugu district, Telangana State, was purposively selected keeping in view the existing target sample i.e. Gothi koya tribes. A total of 60 samples from three villages' viz., Raibandam, Chintalamore and Bangarupalli under ITDA (Integrated Tribal Development Agency), Eturnagaram were selected purposively for this study. Twenty respondents from each village were chosen, purposively. Thus, a total of 60 respondents were selected. An interview schedule was used to collect the profile characteristics and livelihood security of the tribe. Profile characteristics namely age, family size, family type, education, occupation, landholding, social participation, information-seeking behaviour, extension contact, mass media exposure and awareness on government schemes were studied. To assess the livelihood security of Gothi Koya tribe, the livelihood security index developed by (Hari Ram et al., 2018) was adopted with slight modifications. The index contains 4 components i.e. Food Security, Infrastructure Security, Health and Sanitation Security and Water Security.

\section{RESULTS AND DISCUSSION}

Characteristics of respondents: The majority of the respondents $(50 \%)$ fall under the age group between 20 30 years followed by 30 per cent of the students who were in the age group between 30-40 years. Only 20 per cent students were in age group between $40-50$ years. This might be due to more number of respondents who were married at a younger age and hold responsibility for their households were being selected as respondents (Table 1).

Table 1. Distribution of the respondents according to their profile characteristics $(N=60)$

\begin{tabular}{|c|c|c|}
\hline Categories & No. & $\%$ \\
\hline \multicolumn{3}{|l|}{ Age } \\
\hline $20-30$ years & 30 & 50 \\
\hline 30 - 40 years & 18 & 30 \\
\hline 40 - 50 years & 12 & 20 \\
\hline \multicolumn{3}{|l|}{ Educational Qualification } \\
\hline Illiterate & 51 & 85.00 \\
\hline Primary Education & 09 & 15.00 \\
\hline Secondary Education & 0 & 0 \\
\hline Intermediate & 0 & 0 \\
\hline Graduation and Post-Graduation & 0 & 0 \\
\hline \multicolumn{3}{|l|}{ Source of Income } \\
\hline Agriculture + Labour & 55 & 91.67 \\
\hline Handcrafts & 1 & 1.67 \\
\hline Tailoring & 1 & 1.67 \\
\hline Driver & 1 & 1.67 \\
\hline VegeTable Vendor & 2 & 3.33 \\
\hline \multicolumn{3}{|l|}{ Marital Status } \\
\hline Married & 60 & 100 \\
\hline Unmarried & 0 & 0 \\
\hline \multicolumn{3}{|l|}{ Family Size } \\
\hline Small & 47 & 78.33 \\
\hline Medium & 13 & 21.67 \\
\hline Large & 0 & 0 \\
\hline \multicolumn{3}{|l|}{ Family Type } \\
\hline Nuclear & 51 & 85 \\
\hline Joint & 9 & 15 \\
\hline \multicolumn{3}{|l|}{ Landholding } \\
\hline Marginal & 3 & 5 \\
\hline Small & 26 & 43.33 \\
\hline Semi-Medium & 23 & 38.33 \\
\hline Medium & 4 & 6.67 \\
\hline Big & 2 & 3.33 \\
\hline
\end{tabular}


It could be seen from the above Table 1 . that majority $(85.00 \%)$ of the respondents were illiterate and only 15 per cent of respondents were in primary education. No other respondent had completed secondary school or higher education. This could be because, as a result of their migration from one location to another, they were unable to complete their education, and they were also more involved in household chores and taken care of their younger siblings from a young age. The traditional living style linked with their poor economic and social status was also one of the reasons. The tribes were isolated from local villages and cities and staying in the jungle. These results were in accordance with the study (Radhakrishnan et al., 2017 ) in their study they revealed that there were no schools in the village and found it difficult to mingle with others due to the language barrier.

It was apparent from the above Table 1. that majority $(91.67 \%)$ of respondents were employed in agriculture + labour, followed by a vegetable vendor (3.33\%), and an equal per cent of respondents were employed in handicraft (1.67\%), tailoring (1.67\%), and driving (1.67\%). The word "Podu" comes from the vernacular language Telugu. Podu is a form of shifting agriculture by using the slash and burn method. Podu cultivation was highly practised among the Gothi Koya tribe. This could be due to their settlement in a forest area where they rely on natural resources and have difficulty finding other sources of income."It refers to the current status of respondents concerning their marital status. It can be seen that a cent per cent of the respondents was married. This might be due to insecurity, early marriages, low educational and economic status of the respondents. The results were by Radhakrishnan et al., 2017 that these tribes do not educate girl children. There is a lot of children- marriages practices among them. The majority (78.33\%) of the respondents belonged to small families (Up to 5 members) followed by 21.67 per cent medium families (6 to 10 members) and there were no large families (11 and above). The reason might be due to separation from parents and build a new house for living independently. These results were in line with (Swathi, 2018) that as soon as the person gets married, he builds a new house in the village and lead an independent life with his wife and newborns.

It could be clearly that majority $(85.00 \%)$ of the respondents belongs to nuclear family followed by joint family $(15.00 \%)$. This might be due to the separation from their parents and living with their wife and children. Due to a greater number of small size families, the respondents were under nuclear family type. These results in line with (Swathi, 2018) that tribal does prefer to lead an independent life and nuclear families are ultimate basis of the tribe.

The above Table clearly shows that the nearly half (43.33\%) of the respondents were small (1.01 to 2.00 hectare) landholding followed by semi medium (2.01 to 4.00 hectares) landholdings ( $38.33 \%)$, medium (4.01 to 10.00 hectares) landholding 6.67 per cent, only 5 per cent tribes hold marginal landholding (up to 1.00 hectares) and remaining 3.33 per cent tribes had big landholding (10.0 to above hectares).

Social Participation: The above Table 2 indicated that the majority of the respondents always involved in village meetings $(90.00 \%)$, tribal organization activities $(86.67 \%)$, gram panchayath activities $(61.67 \%)$ and half of the respondents occasionally participate in the political activities (51.67\%). The study also revealed that there were no self-help groups and training sessions conducted in the villages.

Table 2. Distribution of respondents according to their social participation $(\mathrm{N}=60)$

\begin{tabular}{lccc}
\hline Social Participation & \multicolumn{4}{c}{ Always (\%) } & Sometimes (\%) & Never (\%) \\
\hline Gram Panchayath & 61.67 & 18.33 & 20.00 \\
Self Help Groups & 0.00 & 0.00 & 100.00 \\
Training & 0.00 & 0.00 & 100.00 \\
Political activities & 1.67 & 51.67 & 46.67 \\
Village meeting & 90.00 & 3.33 & 6.67 \\
Tribal Organizations & 86.67 & 3.33 & 10.00
\end{tabular}

Extension Personnel - Awareness \& Frequency of Contact : It could be clearly seen that most of all respondents were aware of NGO workers $(100.00 \%)$ followed by ITDA officials (71.70\%) and not aware of any other extension personnel. This might be due to the inaccessible location of these villages and no proper transport facilities to the villages.

It could be clearly seen from above Table 3 that majority $(96.70 \%)$ of the respondents had regular NGO contact followed by medium extension contact (3.30\%). Nearly half $(53.30 \%)$ of the respondents had contact with ITDA officials followed by medium level (46.7\%). It also revealed that respondents had no contact and even they were not aware of remaining extension personnels. 
participation and living in the forest. These results were in line with Mohanty et al. (2013) in their study revealed that the majority of the respondents had a low level of extension agency contact followed by moderate and high.

Table 3. Distribution of respondents according to their awareness on extension personnel $(N=60)$

\begin{tabular}{llllll}
\hline \multirow{2}{*}{ Category } & \multicolumn{2}{c}{ Awareness (\%) } & \multicolumn{3}{c}{ Freq. of contact (\%) } \\
& A & NA & R & O & N \\
\hline AEO & 0.00 & 100.00 & 0 & 0 & 100 \\
AO & 0.00 & 100.00 & 0 & 0 & 100 \\
Scientists & 0.00 & 100.00 & 0 & 0 & 100 \\
ITDA officials & 71.70 & 28.30 & 53.3 & 46.7 & 0 \\
NGO & 100.00 & 0.00 & 96.7 & 3.3 & 0 \\
\hline
\end{tabular}

$\mathrm{A}=$ Aware $\quad \mathrm{NA}=$ Not Aware $\mathrm{R}=$ Regularly

$\mathrm{O}=$ Occasionally $\mathrm{N}=\mathrm{Never}$

Information seeking behaviour: The above Table 4 . indicated that most of all respondents mostly seek information from the ANM (100.00\%), followed by NGO $(98.30 \%)$, the doctor $(83.30 \%)$ and health visitors $(60.00 \%)$. This might be due to their frequent contact with the NGO, ANM and Health faculty, as these officials visit their villages regularly.

Table 4. Distribution of respondents according their information seeking behaviour $(\mathrm{N}=60)$

\begin{tabular}{lllll}
\hline Info.seeking behaviour & $\mathrm{F}(\%)$ & $\mathrm{O}(\%)$ & $\mathrm{R}(\%)$ & $\mathrm{N}(\%)$ \\
\hline Neighbors & 10.00 & 60.00 & 30.00 & 0.00 \\
Local leaders & 3.30 & 36.00 & 8.30 & \\
Panchayath officials & 3.30 & 3.30 & 33.30 & \\
NGO & 98.30 & 1.70 & 0.00 & 0.00 \\
AEO/AO & 0.00 & 0.00 & 0.00 & 60.00 \\
Bank officials & 0.00 & 0.00 & 0.00 & 60.00 \\
ITDA officials & 0.00 & 0.00 & 53.30 & 46.70 \\
Doctors & 83.30 & 16.70 & 0.00 & 0.00 \\
ANM & 100.00 & 0.00 & 0.00 & 0.00 \\
Health visitors & 60.00 & 40.00 & 0.00 & 0.00 \\
\hline
\end{tabular}

$\mathrm{F}=$ Frequently; $\mathrm{O}=$ Occasionally; $\mathrm{R}=$ Rarely; $\mathrm{N}=$ Never

Table 5. Distribution of respondents according their mass media exposure $(N=60)$

\begin{tabular}{lccc}
\hline Exposure & Daily $(\%)$ & Occasionally $(\%)$ & Never $(\%)$ \\
\hline Radio & 0.00 & 0.00 & 100.00 \\
Television & 0.00 & 0.00 & 100.00 \\
Mobile phone & 46.70 & 53.30 & 0.00 \\
Newspaper & 0.00 & 0.00 & 100.00 \\
Farm magazines & 0.00 & 0.00 & 100.00 \\
Books on agri. & 0.00 & 0.00 & 100.00 \\
Internet & 0.00 & 0.00 & 100.00 \\
\hline
\end{tabular}

Mass media exposure : Table 5 clearly shows that half of the respondents $(53.30 \%)$ were occasionally exposed to mobile phones, while 46.70 per cent were exposed to mobile phones daily. It was also found that respondents had no exposure to other forms of media such as radio, television, the internet, or other print materials. This was due to a lack of availability and access to alternative media channels.

Awareness of tribal development schemes and services : Table 6 is apparent that the majority $(75.00 \%)$ of the respondents were aware of KCR kit (Ammavadi) followed by kalyana lakshmi $(50.00 \%)$, free hostel facility (48.33\%), and free education \& scholarship (41.67\%). The obtained results were due to most of all respondents were married with children and received the KCR kit after their delivery. Immediately after birth, the mother is given a KCR Kit, which contains 16 items required to keep newborn infants (neonates) warm and hygienic. They were also unaware of other remaining schemes.

Table 6. Distribution of respondents according to their awareness on tribal schemes and services $(N=60)$

\begin{tabular}{lllll}
\hline \multirow{2}{*}{ Tribal scheme } & \multicolumn{2}{l}{ Awareness } & \multicolumn{2}{l}{ Services } \\
& Yes & $\%$ & No & $\%$ \\
\hline Kalyana lakshmi & 30 & 50.00 & 30 & 50.00 \\
Promotion of inter caste marriages & 0 & 0 & 60 & 100.0 \\
Crop insurance scheme & 03 & 5.00 & 57 & 95.00 \\
Crop loans & 21 & 35.00 & 39 & 65.00 \\
Supply of seeds to farmers & 20 & 33.33 & 40 & 66.67 \\
Farm mechanization & 02 & 03.33 & 58 & 96.67 \\
Farmer insurance scheme & 0 & 0 & 60 & 100.0 \\
KCR Kit(Ammavadi) & 45 & 75.00 & 15 & 25.00 \\
Free hostel facility & 29 & 48.33 & 31 & 51.67 \\
Free education \& scholarship & 25 & 41.67 & 35 & 58.33 \\
\hline
\end{tabular}

Table 7. Distribution of the respondents according to their agriculture production $(\mathrm{N}=60)$

\begin{tabular}{lll}
\hline Products & Yes $(\%)$ & No $(\%)$ \\
\hline Rice & 100 & 0 \\
Wheat & 78.33 & 21.67 \\
Pulses & 100.0 & 0.0 \\
Oilseeds & 6.67 & 93.33 \\
Cotton & 0.0 & 100.0 \\
Sugarcane & 0.0 & 100.0 \\
\hline
\end{tabular}

Production of Agricultural Products : From the above Table 7 indicated that most of all respondents cultivated three-grain crops: rice (100\%), Pulses (100\%) and Wheat (78.33\%). Only 6.67 per cent of respondents cultivated 
oilseed crops in their farms. The remaining cotton and sugarcane crops were not grown in the research area. Purpose of Agricultural Production: The majority of the respondents produced agricultural products for their own consumption rather than sale, only a few (10\%) respondents produced for both sale and family use (Table 8). This implies that due to lack of marketing, transportation and storage facilitates the respondents were using the products for their own consumption.

Table 8. Distribution of respondents according to their purpose of agriculture production $(N=60)$

\begin{tabular}{lll}
\hline Purpose of agriculture production & Yes $(\%)$ & No $(\%)$ \\
\hline Family use & 54 & 90 \\
Sale use & 0 & 0 \\
Both family and sale & 6 & 10 \\
\hline
\end{tabular}

Livelihood security of selected target population : From the above Table 9, it indicated that the majority $(78.3 \%)$ of the respondents expressed that they have sufficient food throughout and only 21.7 per cent responded they didn't had sufficient food. The majority of the respondents expressed they don't consume fruits $(70 \%)$, meat $(58 \%)$, fish $(83.3 \%)$ and dairy products $(85 \%)$. More than half $(65 \%)$ of the respondents were not consuming thrice a day. This implies that the majority of the respondents had sufficient food in their household but we're not consuming thrice a day because of multiple works such as own agriculture + labour.

Table 9. Distribution of respondents according to their food security $(N=60)$

\begin{tabular}{lll}
\hline Components of livelihood security & Yes\% & No\% \\
\hline Sufficient food & 78.3 & 21.7 \\
Do you consume fruits daily? & 30 & 70 \\
Do you consume vegeTables daily? & 70 & 30 \\
Would not have enough food? & 8.3 & 91.7 \\
Do you consume meat twice in a week? & 41.7 & 58.3 \\
Do you consume fish in a twice in a week? & 16.7 & 83.3 \\
Do you consume dairy products daily? & 15 & 85 \\
Do you eat thrice a day? & 35 & 65 \\
\hline
\end{tabular}

From the above Table 10, it indicated that more than half $(70 \%)$ of the respondents had transportation facility followed by irrigation facility (43\%). Most $(100 \%)$ of all respondents expressed that they don't have pucca roads, post and telegraph accessibility, electricity, educational institutions and internet facility in their village or households. This might be due to the tribes living in the forest and had no proper service provided to them. The results were by Radhakrishnan et al., 2017 that these settlements are not recognized as a revenue village and so the people living in this settlement are not provided any basic services to live like ration cards etc. Their huts are not given electricity services.

Table 10. Distribution of respondents according to their infrastructure security $(N=60)$

\begin{tabular}{lll}
\hline Infrastructure Security & Yes $(\%)$ & No $(\%)$ \\
\hline Pucca approach roads & 0 & 100.00 \\
Post and telegraph offices & 0 & 100.00 \\
Proper transportation facility & 70 & 30.00 \\
Irrigation facility? & 43 & 17.00 \\
Electricity facility & 0 & 100.00 \\
Educational institution? & 0 & 100.00 \\
Internet facility & 0 & 100.00 \\
\hline
\end{tabular}

Table 11. Distribution of respondents according to their health and sanitation security $(N=60)$

\begin{tabular}{lll}
\hline Health and sanitation security & Yes\% & No\% \\
\hline Family planning & 71.7 & 28.3 \\
Children immunized & 71.7 & 28.3 \\
Incidence of diarrhoea last 30 days & 43.3 & 56.7 \\
Incidence of fever in last 30 days & 20 & 80 \\
Other sickness in last 30 days & 61.7 & 38.3 \\
Consult doctor in time & 58.30 & 41.70 \\
Medical shop facility & 0 & 100 \\
Visit by the health workers & 100 & 0 \\
Household have latrine facility & 0 & 100 \\
Soap or detergent for washing hands & 28.3 & 71.7 \\
\hline
\end{tabular}

It could be seen from the above Table 11, that the majority of the respondents were aware of family planning $(71.7 \%)$ and got their children immunized (71.7\%). Nearly 61.7 per cent suffered from sickness, one fourth $(43.3 \%)$ of the respondents had suffered from diarrhoea in the last 30 days and expressed that more than half $(58.3 \%)$ of them consulted the doctor in time. Only 28 per cent of respondents wash their hands with soap or detergent. Respondents (100\%) had no latrine facility in their household. This revealed that majority of the respondents were with poor hygienic practices which led to health-related problems in the last one month. These findings were consistent with Singh and Sadangi (2012), who discovered that in the absence of toilet facilities, all families $(100 \%)$ relied on open space for defecation because no household had septic tank facilities in their homesteads. This resulted in several 
unsanitary conditions in their habitat and surrounds.

Table 12. Distribution of respondents according to their water security $(N=60)$

\begin{tabular}{lll}
\hline Water Security & Yes\% & No\% \\
\hline Availablity of water storage facility & 26.7 & 73.3 \\
Availablity safe drinking water & 0 & 60 \\
Availablity of enough water & 43.3 & 56.7 \\
Availablity of natural water source & 88.3 & 11.7 \\
Facility to make water clean and safe & 0 & 100 \\
\hline
\end{tabular}

It could be seen from the above Table 12 that the majority $(88.3 \%)$ of the respondents had natural water sources and 43.30 per cent had sufficient water to meet their needs. At the same time, most of all respondents (100\%) expressed that they had done nothing to ensure safe drinking water. More than half $(60 \%)$ of the respondents expressed they do not have access to safe drinking water. These respondents need to walk miles to fetch water for their daily use. The results show that there is a lack of awareness about hygienic practices, storage methods, and a lack of fresh and clean water to meet the basic necessity.

Association between profile characteristics and livelihood security : It could be indicated (Table 13) the correlation between personal profile variables and food security of Gothi koya tribe. It can be seen that there was a positive significant relationship between education with food security, health \& sanitation security, infrastructure security and water security as dependent variables at $1 \%$ level $(\mathrm{p}<0.01)$. The other personal profile variables given in the Table were found not significant at $5 \%$ level.

From the results, it can be explained that as education increases their food security, health and sanitation security, infrastructure security and water security increases.

Table 14. Association between personal profile and livelihood security $(N=60)$

\begin{tabular}{lc}
\hline Personal profile variables & Livelihood Security(r-value) \\
\hline Age & -.187 \\
Family Size & -.048 \\
Family Type & $-.213^{*}$ \\
Education & $.660^{* *}$ \\
Occupation & .124 \\
Landholding & .027 \\
Social Participation & .098 \\
Information Seeking Behaviour & -.166 \\
Awareness on Schemes & .043 \\
\hline
\end{tabular}

** Correlation is significant at the 0.01 level (2-tailed)

The Table 14 indicated the correlation between personal profile variables and livelihood security of Gothi koya tribe. It can be seen that there was a significant relationship between education and livelihood security, as the dependent variable at $1 \%$ level $(p<0.01)$ and the family type variable found negatively significant at $5 \%$ level. The other personal profile variables given in the table were found non-significant with livelihood security at $5 \%$ level.

It can be explained from the results that as education increases their livelihood security also increases. The theory which emerged to explain education variable relation to livelihood security was given by Hari Ram et al. (2018) that education was found positively significant related with the livelihood security of the respondents. The author concluded that increasing the value of education, livelihood security of the respondents can be increased.

Table 13. Association between Profile Characteristics and Livelihood Security Components $(\mathrm{N}=60)$

\begin{tabular}{lcccc}
\hline Personal profile variables & $\begin{array}{c}\text { Food security } \\
\text { (r-value) }\end{array}$ & $\begin{array}{c}\text { Health and sanitation } \\
\text { security (r-value) }\end{array}$ & $\begin{array}{c}\text { Infrastructure } \\
\text { (r-value) }\end{array}$ & $\begin{array}{c}\text { Water security } \\
\text { (r-value) }\end{array}$ \\
\hline Age & -.185 & -.197 & -.145 & .073 \\
Family Size & -.049 & .020 & -.098 & -048 \\
Family Type & -.244 & -.199 & -.244 & -.146 \\
Education & $.776^{* *}$ & $.630^{* *}$ & $.385^{* *}$ & $.506^{* *}$ \\
Occupation & .087 & .064 & .158 & .128 \\
Landholding & .004 & .017 & -.006 & .099 \\
Social Participation & .124 & .115 & .075 & .082 \\
Information Seeking Behaviour & -.153 & -.116 & -.124 & -.040 \\
Awareness on Schemes & .180 & .031 & .103 & -.143 \\
\hline
\end{tabular}

**Correlation is significant at the 0.01 level (2-tailed) 


\section{CONCLUSION}

The majority of respondents were illiterate, had little contact with extension personnel, participated in few social activities, had no access to mass media, and owned only a small amount of land. The majority of respondents seek information from an ANM, an NGO worker, a doctor, or a health visitor. Respondents, on the other hand, reported a lack of access to and control over productive resources and services, as well as a lack of access to basic amenities. They are unaware of development programmes and policies focused on improving their standard of living. Podu cultivation is highly practised in the study area. The main source of income comes from agriculture and agriculture labour. Only three-grain crops were grown, and they were mostly consumed rather than sold. Have no idea how to use natural resources and create revenue-generating activities. Except for the education variable, respondents' livelihood security was found to be non-significant. It proved that improved education has facilitated in enhancing livelihood security. "The findings of the study recommended that the government, NGOs, and other policymakers should plan a developmental discourse and advocate policies for scrutinising livelihoods. The comprehensive approaches are required to improve the overall conditions and sustainability of the Gothi Koya tribe community, as well as to promote income generation.

\section{CONFLICTS OF INTEREST}

The authors declare that they have no conflicts of interest.

\section{REFERENCES}

Chambers, R. (1989). Editorial introduction: vulnerability, coping and policy. IDS Bull., 2 (2) : 1-7.

Frankenberger, T. (1996). Measuring household livelihood security: an approach for reducing absolute poverty. Food Forum, No. 34. Washington, DC, USA.

Hari Ram, B.; Sujeet Kumar, J.; Chandan Kumar, R. and Yadav, R. (2018). Assessment of livelihood security of tribal farmers: A case study from tribal area of Madhya Pradesh, India. Intl. J. of Current Microbiology Applied Sci., 7 (3) : 1135-1141. doi: https://doi.org/10.20546/ijcmas.2018.703.135

Mohanty, A.K.; Lepch, B and Kumar, A. (2013). Constraint's analysis in adoption of vegetable production technologies for livelihood perspective of tribal farmers in North Sikkim. Indian Res. J. of Ext. Edu., 13 (2) : 51-56.

Radhakrishnan, S.; Antony; Vedanayagam, J.B. and Suresh Raj, Y.S. (2017). Internally displaced tribes. Intl. J. of Res., $4(6)$ : 737-743.

Shincy, N.I. (2009). Livelihood analysis of IRULA tribe of Attappady. M.Sc. Thesis. Kerala Agricultural University.

Singh, Abha and Sadangi, B.N. (2012). Livelihood patterns and resource base of tribals in Koraput and Rayagada district of Odisha. Indian Res. J. of Ext. Edu., 12 (Special issue, Vol. I) : 307-312.

Swathi, A. (2018). A study on persistent ethnomedical practices of tribals in Vizianagaram district of Andhra Pradesh. M.Sc. Thesis. Acharya N.G. Rnga Agricultural University. Andhra Pradesh. 